\title{
PENGARUH GAYA KEPEMIMPINAN, LINGKUNGAN KERJA, DAN HARAPAN DOSEN TERHADAP KEPUASAN KERJA
}

\author{
Saur Mangapul Tampubolon
}

\begin{abstract}
The objectives of this research is to find out the effects of leadership style, work environment, and the lecturers or teaching staff satisfaction. The research has been conducted at Pakuan University, Bogor. The method used was a survey with data analysis of path analysis. The respondents were 72 out of 264 total teaching staff in the university. They were selected at random. The research finding are as the followings: (1) leadership style has a direct effect on the lecturer's satisfaction, (2) and also on the work environment has a direct effect on the job satisfaction, (3) the expectation gives a direct effect on job satisfaction, but the leadership style gives and indirect effect on job satisfaction, but the leadership style gives an indirect effect on job satisfaction through expectation, and (4) the working environment has also indirect effect on the job satisfaction through expectation. The conclusion is that the lecturer's satisfaction is affected by the leadership style, work environment and the lecturer's expectation.
\end{abstract}

Keywords: Job satisfaction, University lecturer leadership style, work environment, expectation.

\section{PENDAHULUAN}

Universitas Pakuan (Unpak) di kota Bogor merupakan kelanjutan dan pengembangan dari Universitas Bogor (Unbo) serta merupakan fusi dari beberapa Perguruan Tinggi Swasta (PTS) yang ada di kota Bogor, yaitu: Akademi Bahasa Asing (ABA), Institut Keguruan dan Ilmu Pendidikan (IKIP) PGRI, Akademi Sekretariat dan Manajemen Indonesia (ASMI), Akademi Parwisata Bogor (APB), dan Akademi Ilmu Agama Islam Bogor (AIAIB) yang diselenggarakan oleh Yayasan Pakuan Siliwangi Bogor. Dalam melaksanakan program Tri Darma Perguruan Tinggi, Universitas Pakuan dilengkapi dengan perangkat subordinasi organisasi yang bertanggung jawab terhadap pendidikan dan pengajaran, penelitian, dan pengabdian pada masyarakat berbentuk Lembaga Penelitian dan Pengembangan (LPP), Lembaga Pengabdian pada Masyarakat (LPM), Pusat Penjaminan Mutu (PPM), dan Lembaga Pengembangan dan Peningkatan Aktivitas Instruksional (LP2AI). Semua kegiatan subordinasi dilaksanakan oleh dosen, namun belum terinternalisasi program dan hasil kinerjanya kepada para dosen secara komprehensif.

Universitas Pakuan berupaya menata manajemen secara terus-menerus dan berkelanjutan dengan memperhatikan paradigma tetrahedron mutu pendidikan tinggi meliputi: (1) kinerja perguruan tinggi mengacu pada kualitas berkelanjutan, (2) kualitas yang berkelanjutan dilandasi kreativitas, inovasi, dan produktivitas sivitas akademika yang dapat dirancang oleh peran manajemen yang berasaskan otonomi, (3) otonomi perguruan tinggi senafas dengan akuntabilitas tata kelola dan kinerja perguruan tinggi, (4) akuntabilitas publik digambarkan oleh kemudahan memperoleh informasi tentang manajemen dan kinerja Perguruan Tinggi, dan

\footnotetext{
- Dosen Tetap Universitas Pakuan Bogor
} 
diaktualisasikan melalui proses akreditasi, dan (5) tindakan manajerial dalam pengambilan kebijakan di perguruan tinggi berlandas-kan hasil evaluasi internal dan eksternal. Paradigma tetrahedron tersebut mengarah pada pencapaian standar nasional pendidikan yang terdiri atas delapan komponen yang harus dipenuhi semua satuan pendidikan.

Sebab menurut Peters dalam Serian Wijatno (2009:228) bahwa faktor-faktor yang mempengaruhi citra publik perguruan tinggi adalah: (1) gaya kepemimpinan, (2) kebijakan dan strategi, (3) kebijakan manajemen sumber daya manusia, (4) pengelolaan kekayaan, (5) pengelolaan proses, (6) kepuasan karyawan dan konsumen, (7) tanggungjawab sosial, dan (8) harapan dan hasil usaha.

Berdasarkan uraian pelaksanaan program Tri Darma Perguruan Tinggi di Universitas Pakuan, dapat dinyatakan bahwa peranan dosen sangat penting dalam membangun keberhasilan suatu organisasi. Salah satu faktor yang dapat menunjang keberhasilan tersebut adalah kepuasan kerja dosen dan harapan dosen atas kualitas gaya kepemimpinan dalam organisasi. Permasalahan-permasalahan di atas erat kaitannya dengan tingkat kepuasan kerja dosen sebagai sumber daya manusia yang strategis dalam mencapai tujuan Universitas Pakuan. Berdasarkan alasan ini, maka penting untuk meneliti tingkat kepuasan kerja dosen dari berbagai faktor gaya kepemimpinan, lingkungan kerja, dan harapan dosen. Permasalahan yang berkembang sampai saat ini, berdasarkan pengamatan sementara peneliti menunjukkan bahwa masih terdapat kekurangpuasan dosen atas gaya kepemimpinan di lingkungan Universitas Pakuan. Hal ini dapat dilihat dari permasalahan layanan promosi jabatan fungsional, kesejahteraan, beban tugas mengajar, minat dan budaya meneliti, dan lain lain. Tingkat kepuasan kerja dosen yang dimaksud dalam penelitian ini adalah suatu tanggapan perasaan seseorang atau dosen terhadap aspek-aspek yang ada dalam pekerjaannya. Berdasarkan fenomena tingkat kepuasan kerja dosen di Universitas Pakuan, yang paling menarik perhatian peneliti untuk melakukan penelitian adalah tentang pengaruh gaya kepemimpinan, lingkungan kerja, dan harapan dosen terhadap kepuasan kerja dosen, sebab peneliti masih warga baru dalam dunia perguruan tinggi, selama ini peneliti berkecimpung di lingkungan pendidikan dasar dan menengah.

\section{Kepuasan Kerja.}

Kepuasan (satisfaction) dapat dikatakan sebagai sikap (attitude), karena menurut Robbins dan Judge (2009:65) bahwa "Job statisfaction: a positive feeling about ones job resulting from an evaluation of its characteristics". Artinya, kepuasan kerja adalah pernyataan evaluatif baik untuk menyenangkan maupun tidak menyenangkan terhadap obyek, individu atau peristiwa. Kepuasan kerja pada hakikatnya adalah penilaian seseorang terhadap pekerjaannya.

Pengertian di atas didukung pendapat Ivancevich, Konopaske, dan Matteson (2008:141) yang menyatakan bahwa : "Job satisfaction is an attitude that workers have about their job. It results from their perception of the jobs". Artinya kepuasan kerja adalah sikap pekerja terhadap pekerjaan mereka. Hasil kerja tersebut dipersepsikan dari pekerjaannya. Kemudian Wexley dan Yukl mengemukakan bahwa kepuasan kerja adalah "Job satisfaction is the way an employee feel about his or her job, it is a generalized attitudes toward the job based on evaluation of different aspect of the job. A person's attitude toward his job reflect pleasant and unpleasant experiences in the job and his expectation about future experiences". Pendapat ini, juga menjelaskan bahwa kepuasan kerja sebagai perasaan terhadap pekerjaannya, secara umum merupakan sikap terhadap 
pekerjaan yang didasarkan pada evaluasi aspek yang berbeda bagi pekerja. Pemahaman lebih jauh adalah sikap seseorang terhadap pekerjaannya yang menggambarkan pengalaman me-nyenangkan atau tidak menyenangkan dalam pekerjaan dan harapan-harapan di masa mendatang.

Luthans (2002:231-232) mengutip pendapat Schemerhorn bahwa ada enam faktor yang mempengaruhi kepuasan kerja, yaitu: (1) the work itself adalah suatu pekerjaan memerlukan suatu keterampilan tertentu. Sukar-tidaknya suatu pekerjaan dan perasaan seseorang bahwa keahliannya dibutuh-kan dalam melakukan pekerjaan dalam meningkatkan atau mengurangi kepuasan kerja, (2) promotion opportunities adalah faktor yang berhubungan dengan ada tidaknya kesempatan untuk meningkatkan atau mengurangi kepuasan kerja, (3) promotion carrier adalah faktor yang berhubungan dengan ada tidaknya kesempatan untuk memperoleh peningkatan karir selama bekerja, (4) supervision adalah penyelia yang baik berarti mau menghargai pekerjaan bawahannya. Bagi bawahan, penyelia sering dianggap sebagai figur dan sekaligus atasannya, (5) co-workers adalah faktor hubungan antara pegawai dengan atasannya dan pegawai lain baik yang sama maupun berbeda jenis pekerjaan, dan (6) pay adalah faktor pemenuhan kebutuhan hidup yang dianggap layak.

Cecilia Engko (2007:6) menjelaskan bahwa kepuasan kerja dapat dipahami melalui tiga aspek, yaitu: (1) bentuk respon pekerja terhadap kondisi lingkungan pekerjaan, (2) hasil pekerjaan atau kinerja, dan (3) kaitannya dengan sikap lain yang dimiliki oleh setiap pekerja. Smith (1996:56) secara lebih rinci mengemukakan berbagai dimensi dalam kepuasan kerja meliputi: (1) menarik atau tidaknya jenis pekerjaan yang dilakukan karyawan, (2) jumlah kompensasi yang diterima karyawan, (3) kesempatan untuk promosi jabatan, dan (4) kemampuan atasan dalam memberikan bantuan teknis dan dukungan perilaku serta dukungan rekan kerja. Dengan demikian dapat dikatakan gaya kepemimpinan sangat erat hubungannya dengan kepuasan kerja karyawan. Pemimpin yang mendapat respon positif dari karyawan cenderung akan meningkatkan kepuasan kerja karyawan, dan/atau respon positif dari karyawan cenderung akan meningkatkan kepuasan kerja karyawan, demikian juga bila terjadi sebaliknya.

Berdasarkan uraian di atas dapat disintesiskan bahwa kepuasan kerja adalah suatu tanggapan perasaan suka atau kurang suka seseorang terhadap berbagai aspek yang ada dalam pekerjaannya untuk mencapai tujuan organisasi.

\section{Gaya Kepemimpinan.}

Kreitner \& Kinicki (2000:347) menjelaskan bahwa perilaku individu dalam organisasi adalah pemimpin memberikan nasehat, bimbingan, inspirasi, dan motivasi dalam membangun kelompok, menciptakan kesatuan, menyelesaikan perselisihan di tingkat kelompok. Sekaligus membangun budaya dan menciptakan perubahan transformatif di tingkat organisasi.

Menurut Hersey dan Blanchard (1995:114-115) bahwa perilaku pemimpin bergantung pada hubungan antara gaya kepemimpinan dan situasi. Dimensi efektivitas kepemimpinan pada dimensi perilaku tugas adalah kadar upaya pemimpin mengorganisasi dan menetapkan peranan anggota kelompok dalam melaksanakan pekerjaan. Perilaku hubungan adalah kadar upaya pemimpin membina hubungan pribadi dengan para anggota kelompok. Sebagaimana dijelaskan oleh Gary Yukl (2006:15-17) bahwa ada tiga faktor untuk memahami efektivitas kepemim-pinan, yaitu: (1) karakteristik pemimpin meliputi memotivasi, 
kepribadian yang baik, nilai, keyakinan, optimisme, keterampilan dan keahlian, perilaku, integritas dalam etika, taktik pengaruh, dan sifat pengikut; (2) karakteristik pengikut meliputi bercirikan kebutuhan, nilai, konsep diri, keyakinan dan optimisme, keterampilan dan keahlian, sifat dari pemimpinnya, kepercayaan kepada pemimipin, komitmen, dan upaya tugas, kepuasan terhadap pemimpin dan pekerjaan; dan (3) karakteristik situasi meliputi jenis unit organisasi, besarnya unit organisasi, posisi kekuasaan dan wewenang, struktur dan kerumitan tugas, keadaan lingkungan yang tidak menentu, dan ketergantungan eksternal.

Mondy \& Premeaux (2000:331-333) mengemukakan empat gaya dasar kepemimpinan yang berkaitan dengan perilaku pemimpin yaitu: gaya otokratik, gaya laissez-faire, gaya demokratis, dan gaya partisipatif. House dalam Robbins mengidentifikasi empat perilaku pemimpin yang dapat diadopsi oleh seorang pemimpin jalur-tujuan, yaitu: (1) perilaku direktif adalah pemimpin yang menunjukkan dominasi dalam mengarahkan, mengawasi, dan mengatur bawahan secara ketat seperti apa yang dikerjakan oleh bawahan, tujuan kerja, dan standar perilaku bawahan, serta menekankan pada pemenuhan atas peraturan yang ada di dalam organisasi; (2) perilaku suportif adalah pemimpin dan bagaimana caranya, kapan, dimana, dan sebagainya. Perilaku pemimpin lebih banyak membuat perencanaan, membuat jadwal kerja, memberikan perhatian besar pada kesejahteraan dan pemenuhan kebutuhan bawahan. Perilaku pemimpin bersifat terbuka, bersahabat, dan dapat didekati dengan mudah. Pemimpin menciptakan iklim kelompok kerja dan menganggap bawahan sebagai rekan kerja. Kepemimpinan suportif ini mempunyai kesamaan dengan gaya pemimpin berorientasi pada hubungan; (3) perilaku partisipatif adalah pemimpin yang lebih banyak mengkonsultasikan dan mendiskusikan masalah pada bawahan sebelum membuat keputusan. Kepemimpinan ini mempunyai kesamaan dengan gaya kepemimpinan demokrasi pada teori kepemimpinan situasional menurut Hersey dan Blanchard, dan (4) perilaku berorientasi pada prestasi adalah pemimpin yang menetapkan tujuan yang jelas dan mempunyai tantangan besar untuk bawahan. Perilaku pemimpin ini termasuk kinerja berkualitas tinggi dan peningkatan kinerja di masa depan. House juga menyatakan asumsi bahwa perilaku pemimpin bersifat fleksibel dan teori ini secara implisit menyatakan bahwa seorang pemimpin dapat menerapkan perilaku yang mana saja ataupun semuanya, tergantung dari situasi yang dihadapi.

Berdasarkan uraian di atas, dapat disintesiskan bahwa gaya kepemimpinan adalah perilaku pemimpin untuk mempengaruhi bawahan secara situasional dalam mencapai tujuan organisasi dengan pendekatan memberikan pengarahan, memberi dukungan, mengikutsertakan bawahan dalam pengambilan kebijakan, dan memberikan penghargaan kepada bawahan yang berprestasi.

\section{Lingkungan Kerja.}

Persepsi tentang lingkungan kerja bermacam-macam, Schemerhorn (2005: 89) mengemukakan bahwa ada dua macam lingkungan kerja, yaitu: (1) lingkungan umum terdiri atas kondisi budaya, ekonomi, politik, hukum, pendidikan, teknologi, dan lingkungan alam (2) lingkungan khusus berkaitan dengan posisi oganisasi itu sendiri dalam upaya mengembangkan jaringan organisasinya. Oleh karena itu, pembagian lingkungan kerja dijelaskan oleh Franken (1992:456) bahwa lingkungan kerja mempunyai dua aspek penting, yaitu: (1) lingkungan sarana dan prasarana meliputi segala hal yang berkaitan dengan aspek sarana dan prasarana suatu lembaga/organisasi mulai dari rancangan gedung sampai dengan lokasi, 
transportasi umum, fasilitas parkir dan (2) lingkungan psikologis adalah faktorfaktor yang berpengaruh secara psikologis pada pembentukan suatu lingkungan kerja yang terkait dengan kompetensi manusia sebagai pekerja.

Griffin (1987:73-75) membedakan lingkungan organisasi atas dua bagian, yaitu: pertama, lingkungan eksternal (external environment) adalah segala sesuatu di luar batas-batas organisasi yang mempengaruhi kinerja organisasi dan kedua, lingkungan internal (internal environment) adalah kondisi dan kekuatan-kekuatan di dalam organisasi juga lebih berpengaruh terhadap kinerja organisasi. Artinya, lingkungan eksternal, dan lingkungan internal mempengaruhi produktivitas kerja, serta mempunyai hubungan dengan kepuasan kerja.

Berdasarkan uraian teori di atas, maka dapat disintesiskan bahwa lingkungan kerja adalah keadaan lingkungan fisik dan lingkungan non fisik suatu organisasi yang potensial mempengaruhi suasana pelaksanaan pekerjaan baik individu maupun kelompok di tempat kerja.

\section{Harapan.}

Usaha yang dilakukan seseorang dalam suatu organisasi bergantung pada besarnya harapan, sebagaimana dikemukakan oleh Robbins (1998:187) bahwa "expectancy is the strength of a tendency to act in a certain way depends on the strength of an expectation that act will be followed by a given outcome and on the attractiveness of that outcome to the individual". Jadi harapan adalah suatu kekuatan dari kecenderungan untuk bertindak dengan cara tertentu bergantung dari besarnya harapan yang akan diikuti dengan adanya imbalan yang memadai terhadap hasil kerja, dan disesuaikan dengan daya tarik yang dihasilkan oleh individu, sehingga kepercayaan terhadap usaha pencapaian hasil kerja sesuai dengan keinginan bersama.

Hubungannya dengan kecenderung-an untuk bertindak dalam mencapai harapan, Ivancevich \& Michael T. Matteson (1999:158) berpendapat bahwa "expectancy refers to individual's belief regarding the likelihood or subjective probability that a particular behavior will be followed by a particular outcome, and it is most easily thought of as a single-probability statement". Maksudnya, harapan merujuk pada keyakinan individu berkenaan dengan kemungkinan atau probabilitas subyektif bahwa suatu perilaku tertentu akan diikuti dengan hasil tertentu dan paling mudah dipahami sebagai pernyataan probabilitas tunggal. Ini berarti, bahwa hal tersebut merujuk pada suatu kesempatan yang dipersepsikan dari sesuatu yang akan muncul karena perilaku bawahan dan atasan.

Teori harapan berfokus pada tiga hubungan yaitu: (1) hubungan usaha kinerja (effort-performance relationship) adalah kemungkinan yang dirasakan oleh individu yang melakukan sejumlah usaha tertentu akan menghasilkan kinerja tertentu, (2) hubungan kinerja-penghargaan (performance-reward relationship) adalah tingkat sejauhmana individu percaya bahwa bekerja pada tingkat tertentu akan menghasilkan pencapaian yang diinginkan, dan (3) hubungan penghargaan-tujuan pribadi (rewards-personal goals relationship) adalah tingkat sampai sejauh mana penghargaan organisasional memuaskan tujuan pribadi dan daya tarik dari penghargaan yang potensial bagi individu.

Kunci teori harapan adalah memahami sasaran individu dan hubungan antara usaha dan kinerja, antara kinerja dan penghargaan, akhirnya antara penghargaan dan tujuan pribadi bergantung pada tujuan individu dan persepsinya tentang nilai relatif suatu hasil kerja sebagai jalan untuk meraih tujuan individu dan organisasi; karena teori harapan merupakan alternatif untuk model kepuasan; artinya ada 
hubungan kausal yang positif antara faktor motivivasi, harapan, dan kepuasan dalam suatu organisasi.

Kemudian David Nadler dan Lawler dalam Stoner (1996:147) mengemukakan bahwa teori harapan merupakan bagian dari teori motivasi yang menyatakan bahwa orang memilih bagaimana bertindak dari berbagai alternatif tingkah laku berdasarkan harapan apakah ada keuntungan diperoleh dari tiap tingkah laku. Jadi harapan dapat dipahami dari kadar kuatnya keyakinan bahwa upaya kerja optimal akan menghasilkan penyelesaian suatu tugas, tentu akan mendapat nilai harapan +1 .

Berdasarkan uraian di atas dapat disintesiskan bahwa harapan adalah persepsi terhadap hasil kerja yang mungkin dapat dicapai, dan konsekuensi-nya, serta nilai manfaat yang dapat diperoleh sebagai nilai tambah.

\section{METODE}

Metode penelitian menggunakan metode survei kausal dengan teknik analisis jalur (path analysis). Kegiatan penelitian secara ke-seluruhan dilaksanakan pada Universitas Pakuan di Bogor mulai bulan september 2009 hingga maret 2010. Populasi penelitian adalah dosen tetap pada Universitas Pakuan di Bogor dengan ukuran sampel sebanyak 98 dosen.

\section{HASIL DAN PEMBAHASAN}

Berdasarkan hasil temuan penelitian dengan menggunakan teknik analisis jalur melalui substruktur-1 dan substruktur-2 bahwa semua jalur pengaruh antar variabel adalah signifikan, baik untuk pengaruh langsung maupun pengaruh tidak langsung variabel gaya kepemimpinan, lingkungan kerja, dan harapan dosen terhadap variabel kepuasan kerja dosen.

Hal tersebut sesuai dengan teori kepemimpinan tujuan-sasaran (path goal theory of leadership) oleh House dalam Robbins, (1998:361) yang menyatakan bahwa: "Tugas pemimpin adalah mendampingi pengikut dalam meraih sasaran mereka dan memberikan pengarahan dan/atau dukungan yang perlu untuk menjamin sasaran mereka, agar selaras dengan sasaran keseluruhan kelompok atau organisasi, bahkan ditambahkan oleh Gibson (1997:286), pengaruh gaya kepemim-pinan terhadap kepuasan kerja yaitu: "Leader's behavior effective to the extent that subordinate perceived such behavior as source of immediate satisfaction or instrument of future satisfaction". Artinya, gaya kepemimpinan yang efektif mampu mengarahkan bawahan sesuai dengan tujuan yang telah ditetapkan sebagai sarana peningkatan kepuasan kerja dosen dan karyawan.

Oleh karena itu, penerapan path goal theory of leadership, menurut House dalam George E Jones (2005:387) oleh pemimpin harus efektif memilih keempat perilaku baik sebagian atau sekaligus secara situasional, yaitu: (1) directive leader, (2) supportive leader, (3) participative leader, dan (4) achievement-oriented leader. Karena penerapan gaya kepemimpinan yang tepat akan bermakna pada dua proposisi penting dalam pendekatan manajemen organisasi nirlaba di perguruan tinggi swasta, yaitu: (a) gaya kepemimpinan menjadi sumber kepuasan langsung atau sebagai sarana untuk mencapai tujuan organisasi di masa mendatang dan (b) gaya kepemimpinan bersifat memotivasi untuk memenuhi harapan dosen dan kepuasan kerja dosen dengan dukungan lingkungan kerja baik fisik maupun non fisik yang berkualitas.

Hal tersebut terbukti dari hasil temuan dalam penelitian ini bahwa pengaruh langsung positif gaya kepemimpinan dan lingkungan kerja lebih besar dari pada pengaruh tidak langsung melalui variabel antara yaitu variabel harapan dosen. 
Sehingga variabel antara (intervening variable) merupakan variabel strategis dalam model path-goal theory of leadership; artinya sesuai dengan tuntutan model teoretik yang telah dibahas pada bab II. Hasil penelitian membuktikan bahwa kualitas variabel antara kedua substuktur model jalur hampir sama. Fakta penelitian menunjukkan bahwa pemimpin di lingkungan Universitas Pakuan banyak berkomunikasi langsung dengan para dosen; karena jabatan pemimpin merupakan jabatan tambahan yang bersifat struktural, namun jabatan fungsionalnya adalah dosen; maka pendekatannya harus situasional, dan persuasif, serta familiar.

Sehubungan dengan uraian di atas, Hersey (1989:121) mengemukakan teori pengharapan (expectation theory) dengan lingkungan kerja yang berkaitan dengan hubungan antara perilaku seseorang suka atau tidak suka terhadap perilaku pemimpin adalah: (1) If it is satisflying to them, employees will view work as natural and as play, (2) People at work will exercise initiative, self-direction, and self-control on the job if they are committed to the objectives of the organization, (3) The average person, under proper conditions, learns not only to accept responsibility on the job but to seek it, and (4) The average employee values creatively that is, the ability to make good decisions and seeks opportunities to be creative at work. Intisarinya, adanya respon bawahan terhadap lingkungan atau keadaan organisasi, jika keadaan memuaskan, mereka memandang hal tersebut wajar dan dapat diterima. Mereka akan berinisiatif sendiri, mengendalikan diri sendiri dan berkomitmen terhadap pencapaian tujuan organisasi. Pada saat kondisinya lemah akan berusaha untuk bertanggung-jawab terhadap pekerjaannya. Rata-rata dosen menilai kreativitas dan inovasi yang dilakukan oleh para pemimpin menjadi pemicu kreativitas bagi dosen untuk melakukan perbaikan kinerja mereka.

Respon dan sikap para dosen berbeda-beda terhadap kualitas kepuasan kerja tergantung pada persepsi dosen tersebut. Hal ini, terbukti dari temuan hasil penelitian bahwa pengaruh langsung variabel gaya kepemimpinan dan variabel lingkungan kerja lebih besar dari pada pengaruh tidak langsung terhadap kepuasan kerja dosen; sehingga peran variabel antara (intervening variable) tidak begitu besar, namun penting juga, karena variabel antara mempunyai pengaruh langsung terhadap variabel kepuasan kerja dosen; artinya kedua variabel ini mempunyai hubungan kausal yang berarti.

Total pengaruh langsung dan pengaruh tidak langsung baik variabel gaya kepemimpinan maupun variabel lingkungan kerja terhadap variabel kepuasan kerja dosen sangat baik, yaitu sebesar 19\% dan 17\%. Artinya, semakin berkualitas gaya kepemimpinan dan lingkungan kerja di Universitas Pakuan, semakin meningkat harapan dosen dan kualitas kepuasan kerja dosen untuk memberikan layanan pembelajaran dan bimbingan mahasiswa. Total pengaruh keseluruhan antar variabel baik langsung maupun tidak langsung terhadap kepuasan kerja dosen sebesar $62 \%$, dan sisanya 38\% adalah pengaruh variabel lain sebagaimana yang telah diidentifikasi pada bab I. Artinya, banyak faktor-faktor atau variabel yang mempengaruhi kepuasan kerja, bila organisasi nirlaba menerapkan model path-goal theory of leadership. Dengan demikian, penerapan path goal theory of leadership cukup baik untuk organisisi nirlaba, seperti perguruan tinggi swasta (PTS), karena dikelola oleh berbagai karakteristik dan kompetensi dosen yang berbeda, misalnya Universitas Pakuan di Bogor lebih banyak memiliki dosen tetap yang diangkat oleh Yayasan Pakuan Siliwangi dibandingkan dengan PNS dipekerjakan yang ditempatkan oleh Kopertis Wilayah IV Jawa Barat dan Banten, serta sumber investasi pendidikan dan biaya operasional berasal dari sumbangan mahasiswa. 
Jadi untuk membangun corporate culture yang kooperatif dan konstruktif perlu ditingkatkan kualitas gaya kepemimpinan, dan kualitas lingkungan kerja, serta layanan prima agar prinsip manajemen kualitas terpadu (total quality management) di lingkungan Universitas Pakuan membawa makna yang lebih berarti di masa mendatang; dan mengupayakan peningkatan sistem penjaminan mutu internal (SPMI) dan sistem penjaminan mutu eksternal (SPME).

\section{PENUTUP.}

Kesimpulan. Berdasarkan hasil analisis data penelitian dan pembahasan pada bab sebelumnya tentang faktor-faktor yang mempengaruhi kepuasan kerja dosen pada Universitas Pakuan di Bogor dapat disimpulkan bahwa terdapat: (1) Pengaruh langsung positif gaya kepemimpinan terhadap kepuasan kerja dosen; (2) Pengaruh langsung positif lingkungan kerja terhadap kepuasan kerja dosen; (3) Pengaruh langsung positif harapan dosen terhadap kepuasan kerja dosen; (4) Pengaruh langsung positif gaya kepemimpinan terhadap harapan dosen; dan (5) Pengaruh langsung positif lingkungan kerja terhadap harapan dosen.

Saran. Berdasarkan kesimpulan dan implikasi di atas, dapat dikemukakan beberapa saran dalam peningkatan kualitas kepuasan kerja dosen: (1) Hendaknya para pemimpin mem-perbaiki kualitas gaya kepemimpinannya, baik melalui kualifikasi akademik maupun penerapan perilaku mengarahkan, mendukung gagasan-gagasan atau inovasi, melibatkan dosen dalam pengambilan kebijakan sesuai dengan keahliannya, dan memberikan penghargaan atas prestasi kerja dengan berperilaku adil, obyektif, dan transparan, agar dosen bekerja penuh dengan harapan untuk memuaskan semua pihak. (2) Perlu adanya upaya perbaikan kualitas lingkungan kerja baik lingkungan fisik berupa fasilitas kerja maupun lingkungan non fisik berupa hubungan sivitas akademika dan masyarakat sekitar dalam membangun citra publik Universitas Pakuan. (3) Hendaknya dosen memberikan layanan prima bagi stakeholders Universitas Pakuan, dan meningkatkan kualifikasi akademik sebagai modal membangun corporate culture melalui pelaksanaan program Tri Darma Perguruan Tinggi yang akan tercermin dalam sistem penjaminan mutu internal dan sistem penjaminan mutu eksternal. (4) Hendaknya, para pemimpin meningkatkan layanan kepada dosen melalui pemenuhan harapan dosen, antara lain: (1) desiminasi perkembangan peraturan kepegawaian, (2) promosi jabatan fungsional dan kenaikan pangkat/ golongan, dan sertifikasi dosen, (3) promosi jabatan, dan lain lain; karena akan berdampak terhadap peningkatan kepuasan kerja dosen. (5) Perlu adanya upaya peningkatan kualitas dan pengembangan lingkungan kerja sebagaimana yang diharapkan semua pihak, karena jumlah mahasiswa yang diterima di Universitas Pakuan semakin meningkat/bertambah.

\section{DAFTAR RUJUKAN}


Franken, Robert E., Human Motivation, California: Books Publishing Compay, 1992

Griffin, Ricky, Management, Boston: Houghton Mifflin, Company, 2002

Hersey, P. and K. H. Blanchard, Management of Organizational Behavior : Utilizing Human Resources, New Jersey: Prentice-Hall International, Inc, 1993

Ivancevich John M. \& Michael T. Matteson, Organizational Behavior and Management, New York: McGraw-Hill, Inc, 2008

Kreitner, Robert and A. Kinicki. Organizational Behavior, New York: McGraw-Hill Companies, Inc, 2000 \& 2008

Luthans, Fred, Organizational Behavior, New York: The McGraw-Hill, Co, 2002

Mondy, R. Wayne, A. Sarplin and Shane R. Premeaux. Management : Concepts, Practices, and Skills. Boston : McGraw-Hill, Inc, 2000

Robbins S. P. \& Timothy A. Judge, Organizatonal Behavior, New York: Upper Saddle River, 2009

Smith, R. E., Effects of Coping Skills Training on Generalized Self-efficacy and Locus of Control, Journal of Personality and Social Psychology, 56 (2), 1996/1989

Stoner, James A. F., Management, New Jersey : Prentice-Hall, Inc, 1996 